\title{
Research Performance Assessment Based on T-Indicator
}

\author{
Ling Zhang, Xin Tan, Qing Du, Juan Wang \\ Human Resources Department, Tianjin University, Tianjin, China \\ Email: rscwangjuan@tju.edu.cn, lingzhang@tju.edu.cn
}

Received April 12, 2012; revised May 16, 2012; accepted May 29, 2012

\begin{abstract}
A novel indicator named after Tianjin University (TJU)-T-indicator-was investigated as an effective supplement of established Article Assessment System of Tianjin University, aiming to correct differences among fields. Based on normalized citation counts, T-indicator could give the order of research performance of researchers or groups in different disciplines. Weighted citation analysis was also introduced in this method to judge the contribution of researchers to their research outcomes. A given example was used to thoroughly discuss this evaluation method, via the application of derivative indices, including $\mathrm{T}_{\text {year }}, \mathrm{T}_{\text {average }}, \mathrm{T}_{\text {total }}$ and weighted- $\mathrm{T}_{\text {total }}$.
\end{abstract}

Keywords: Research Performance Assessment; TJ-Indicator; Normalization; Citation Counts

\section{Introduction}

Research performance assessment (RPA) plays important roles in universities and research institutions, especially in the process of recruitment, academic promotion, offering tenure, granting, etc. The general indices of RPA include publications, patents, awards, and grants. It is hard to evaluate the quality level of patents, awards, and grants among different institutions and countries as there is no same standard. However, journal publication, mostly published after peer reviews, is a good and unique index for internal and external comparison. Nowadays, journal publication has been widely used officially or subconsciously in the process of RPA.

An article assessment system has been successfully established based on both Tianjin University and nine key Chinese Universities' academic disciplinary benchmarks [1]. With this scientific benchmarking system, the quality of a researcher's papers could be easily located in a percentile scale in corresponding field and within certain groups. Several factors, including total number of papers, order of authors, impact factor of journals, citation count, h-index [2], e-index [3], a-index [4], m-quotient [2], as well as weighted citation analysis [5], were also utilized for both quantity and quality analysis.

This article assessment system has played a significant role as an important part of RPA in Tianjin University. However, with unique advantages in comparing researchers or groups in a same field, it is hard to tell their RPA in different fields. To improve this article assessment system, citation counts were normalized for correcting differences among fields. Breaking the boundary of disciplines, this modified citation-based article as- sessment system could easily give the order of research performance of researchers or groups even in different disciplines.

\section{Methods}

The average number of citation count of all TJU publications from Scopus citation database are obtained for each discipline and for each year from the year of 2001 to the year of 2009, based on the accumulation of citations from the year of publication to the current year (Equation (1)).

$$
A C_{y_{j}}=\frac{1}{n_{j}} \sum_{i=1}^{n_{j}} C_{i, j}
$$

where $C_{i, j}$ are the citations received by the $i^{\text {th }}$ paper in the year $j$, and $n_{j}$ is number of papers published in the year $j$. On the left hand of Equation (1), $A C_{j}$ represents the average number of citations received in the period from year $j$ to 2009 by papers published in the year $j$.

To obtain the total T-indicator $\left(\mathrm{T}_{\text {total }}\right)$, annual T-indicator $\left(\mathrm{T}_{\text {year }}\right)$ are required to be calculated firstly: the sum of a researcher or group's actual number of citations of all publications is divided by the above average number for each year in the same discipline (Equation (2)).

$$
T J_{y_{j}}=\frac{1}{m_{j}} \frac{\sum_{i=1}^{m_{j}} C_{i, j}}{A C_{y_{j}}}
$$

where $m_{j}$ is the number of papers published by an individual researcher or a group of researchers in the year $j$, and $T J_{y_{j}}$ is the ratio of the average citations received 
for an individual researcher or a group of researchers in the year $j$, over the average number of citations received in the year $j$ of the whole university, both in the same discipline.

The average number of $\mathrm{T}_{\text {year }}$ is the $\mathrm{T}$-indicator (Equation (3)), and the standard deviation (SD) is also calculated to show the stability of research performance (Equation (4)).

$$
\begin{gathered}
T J_{\text {total }}=\frac{1}{\left(y_{2}-y_{1}\right)} \sum_{j=y_{1}}^{y_{2}} T J_{y_{j}} \\
S D_{T J}=\sqrt{\frac{\sum_{j=y_{1}}^{y_{2}}\left(T J_{y_{j}}-T J_{\text {total }}\right)^{2}}{\left(y_{2}-y_{1}\right)-1}}
\end{gathered}
$$

where $y_{1}$ is the first year of the period in which the research performance of an individual researcher or a group of researchers are required to be analyzed, and $y_{2}$ is last year of this period required to be analyzed.

\section{Results and Discussion}

Table of Mean of Citation Count of all TJU Publications is prepared (Table 1) for 25 disciplines from the year of
2001 to the year of 2009. Total number of TJU publications over 9 years and of each year, as well as the annual mean citation count were all included for every category in this table. For example, in category of "Agricultural and Biological”, total number of TJU publication is 388; the number of publications in the year of 2001 and the mean citation count is 11 and 14.18, respectively.

The following example is taken to discuss the application of T-indicator. Tianjin University announced the competition for a 3-level award funding for research performance, and there are 8 candidates entered the last round. In the process of research publication assessment, as shown in Table 2, all of them are excellent in their research fields, and some of them have similar number of publications (Candidate 3 and Candidate 5), total citation count (Candidate 3 and Candidate 8), and average citation count (Candidate 1 and Candidate 5) as well. Furthermore, considering the property of citation frequency in different research areas, it is very hard to simply compare them via the common indices, including citation count, h-index, e-index, etc., as mentioned above. However, T-indicator, based on normalized citation count, could be conveniently used here to give the order of research performance as a helpful reference to the award

Table 1. The mean of citation count of all TJU publications. The data were collected from Scopus citation database at

\begin{tabular}{|c|c|c|c|c|c|c|c|}
\hline \multirow{2}{*}{ Subject } & \multirow{2}{*}{ Total Pub. } & \multicolumn{2}{|c|}{2001} & \multicolumn{2}{|c|}{2002} & \multicolumn{2}{|c|}{2003} \\
\hline & & No. & Mean & No. & Mean & No. & Mean \\
\hline Agricultural and Biological Sciences & 32 & 11 & 14.2 & 5 & 13 & 16 & 7.94 \\
\hline Arts and Humanities & 0 & 0 & 0 & 0 & 0 & 0 & 0 \\
\hline Biochemistry, Genetics and Molecular Biology & 219 & 36 & 14.6 & 50 & 19.28 & 133 & 9.92 \\
\hline Business, Management and Accounting & 6 & 0 & 0 & 2 & 15.5 & 4 & 0.25 \\
\hline Chemical Engineering & 460 & 126 & 5.32 & 162 & 7.72 & 172 & 6.73 \\
\hline
\end{tabular}
10/08/2010. (The table is too big to present entirely here; for details please refer to the Appendix).

Table 2. Publication details of 8 candidates for the award funding for research performance. The data were collected from Scopus citation database at 20/09/2010.

\begin{tabular}{ccccc}
\hline No. & College & Total pub. & Total citation count & Average citation count \\
\hline 1 & College of Science & 197 & 994 & 5.05 \\
2 & College of Science & 134 & 401 & 2.99 \\
3 & College of Science & 157 & 2619 & 16.68 \\
4 & College of Precision Instrument and Opto-electronics Engineering & 176 & 1098 & 6.24 \\
5 & College of Precision Instrument and Opto-electronics Engineering & 152 & 813 & 5.35 \\
6 & College of Material Science and Engineering & 105 & 493 & 4.7 \\
7 & College of Chemical Engineering and Technology & 67 & 735 & 10.97 \\
8 & College of Environment Science and Technology & 125 & 2677 & 21.42 \\
\hline
\end{tabular}


funding committee.

In Scopus citation database, collected journals are categorized into 25 disciplines; however, due to the relativity among certain fields, publications of some journals are subjected to 2 or even more disciplines. In such case, the average of T-indicators of different disciplines could be used instead, due to the normalized native of T-indicator. For example, Candidate 1 has published 197 articles, which are categorized to "Physics \& Astronomy" (140) as well as "Material Science" (102). Apparently some of the publications are classified to both disciplines by Scopus.

As shown in Table 3, in Discipline 1-the category of "Physics \& Astronomy", averages of citation count of different year were calculated firstly (Row 3), which were then divided by the corresponding average number of citation count of all TJU publications for each year in Table 1, and the quotients obtained (Row 4) were $\mathrm{T}_{\text {year }}{ }^{-}$ indicator. $\mathrm{T}_{\text {total }}(1.53)$ and SD (0.91) were then subsequently calculated. The same method was also been used to calculate the $\mathrm{T}_{\text {total }}(0.83)$ and SD (0.97) of publications in Discipline 2 of "Material Science". Finally $T_{\text {average-year }}$ and $\mathrm{T}_{\text {total }}(1.18)$ were achieved by simply computing the mean value of them in different subjects. SDs indicated the consistency of research performance of Candidate 1 in the same discipline.
As shown in Figure 1, $\mathrm{T}_{\text {average-year }}$ could also show an individual annual research performance. For Candidate 1, his $\mathrm{T}_{\text {average-year }}$ hit the peak (2.83) in the year of 2002, and reached the bottom $(0.22)$ in the year of 2008, presenting a decreasing research performance. However, the $\mathrm{T}_{\text {aver- }}$ age-year of Candidate 2 has gradually climbed up since the year of 2001, and a sudden jump to the maximum of 7.14 appeared in the Year of 2009, demonstrating an increasing research performance. A conclusion could be drawn that both Candidate 1 and 2 are very excellent in their own research field as their $\mathrm{Ts}_{\text {average-year }}$ are almost over 1 , and Candidate 2 showed higher potential in research.

When comparing the research performance among more scholars in different disciplines, $\mathrm{T}_{\text {total }}$ displays unique advantages. As shown in Table 4, $\mathrm{T}_{\text {total }}$ of each candidate was calculated, and from these data, Candidate 8 showed the best research performance with the highest $\mathrm{T}_{\text {total }}$ of 5.47, followed by Candidate 5 and Candidate 4, with 3.19 and 2.69, respectively, and the poorest performance in this group is Candidate 6, showing the lowest $\mathrm{T}_{\text {total }}$ of 1.06 .

For further analysis when considering candidates' contributions to publications, weighted T-indicator is introduced based on weighted citation analysis. The use of weighted citation analysis has been thoroughly discussed elsewhere (Zhang 2009b, Zhang 2010), which is a

Table 3. TJ-indicator and SD of publication of Candidate 1. The data were collected from Scopus citation database at 20/09/2010.

Candidate 1

\begin{tabular}{|c|c|c|c|c|c|c|c|c|c|}
\hline \multicolumn{10}{|c|}{ Discipline 1: Physics \& Astronomy } \\
\hline Year & 2001 & 2002 & 2003 & 2004 & 2005 & 2006 & 2007 & 2008 & 2009 \\
\hline No. of Publication & 5 & 9 & 10 & 13 & 10 & 15 & 14 & 9 & 6 \\
\hline No. of cit. count & 46 & 124 & 101 & 78 & 45 & 51 & 24 & 2 & 2 \\
\hline Aver. of cit. count & 9.2 & 13.78 & 10.1 & 6 & 4.5 & 3.4 & 1.71 & 0.22 & 0.33 \\
\hline $\mathrm{TJ}_{\text {year-indicator }}$ & 2.4 & 3.03 & 2.38 & 1.39 & 1.47 & 1.26 & 0.87 & 0.18 & 0.76 \\
\hline \multicolumn{6}{|c|}{ TJ-indicator $=\mathrm{d} 1.53$} & \multicolumn{3}{|c|}{ Standard Deviation $=0.91$} & \\
\hline \multicolumn{10}{|c|}{ Discipline 2: Material Science } \\
\hline Year & 2001 & 2002 & 2003 & 2004 & 2005 & 2006 & 2007 & 2008 & 2009 \\
\hline No. of Publication & 2 & 6 & 7 & 9 & 5 & 9 & 8 & 4 & 7 \\
\hline No. of cit. count & 0 & 111 & 24 & 72 & 47 & 51 & 11 & 2 & 2 \\
\hline Aver. of cit. count & 0 & 18.5 & 3.43 & 8 & 9.4 & 5.67 & 1.38 & 0.5 & 0.29 \\
\hline $\mathrm{TJ}_{\text {year-indicator }}$ & 0 & 2.64 & 0.4 & 1.57 & 2.4 & 1.31 & 0.4 & 0.26 & 0.46 \\
\hline \multicolumn{5}{|c|}{ TJ-indicator $=0.83$} & \multicolumn{5}{|c|}{ Standard Deviation $=0.97$} \\
\hline $\mathrm{TJ}_{\text {average }}$ & 1.2 & 2.83 & 1.39 & 1.48 & 1.93 & 1.29 & 0.63 & 0.22 & 0.61 \\
\hline \multicolumn{10}{|c|}{$\mathrm{TJ}_{\text {total }}=1.18$} \\
\hline
\end{tabular}




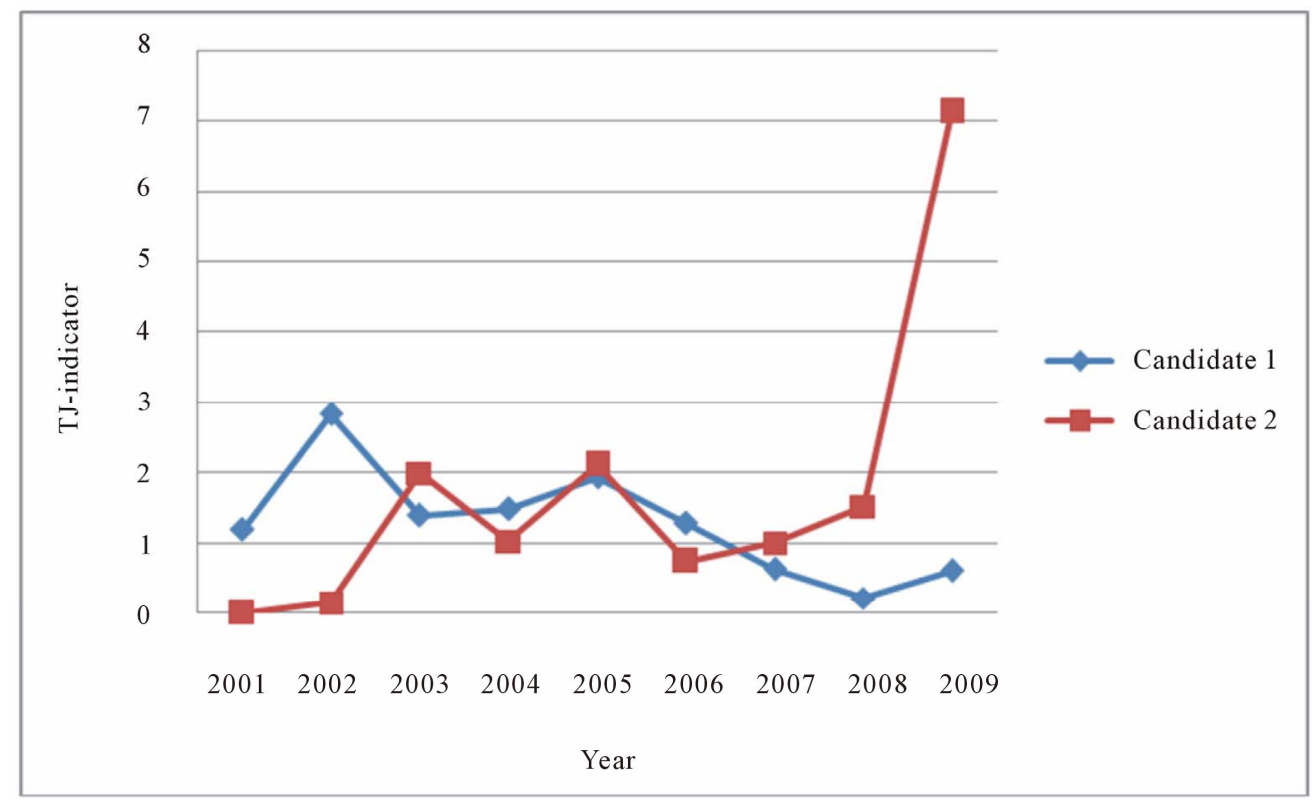

Figure 1. TJ-indicator vs. year of Candidate 1 and Candidate 2. (The data were collected from Scopus citation database at 20/09/2010).

Table 4. TJ-indicator and SD of publication of 8 candidates. The data were collected from Scopus citation database at 20/09/2010.

\begin{tabular}{|c|c|c|c|c|c|c|c|}
\hline \multirow{2}{*}{ No. } & \multicolumn{3}{|l|}{ Discipline 1} & \multicolumn{3}{|c|}{ Discipline 2} & \multirow{2}{*}{$\begin{array}{c}\text { Average } \\
\mathrm{TJ}_{\text {total }}\end{array}$} \\
\hline & Field & $\mathrm{TJ}_{1}$ & $\mathrm{SD}_{1}$ & Field & $\mathrm{TJ}_{2}$ & $\mathrm{SD}_{2}$ & \\
\hline 1 & Physics \& Astronomy & 1.53 & 0.9 & Materials Science & 0.83 & 1 & 1.18 \\
\hline 2 & Engineering & 2.1 & 2.8 & Physics \& Astronomy & 1.09 & 1.7 & 1.6 \\
\hline 3 & Biochemistry, Genetics and Molecular Biology & 1.86 & 1.1 & Engineering & 1.13 & 1.7 & 1.5 \\
\hline 4 & Physics \& Astronomy & 5.23 & 4.5 & Engineering & 0.16 & 0.2 & 2.69 \\
\hline 5 & Engineering & 3.1 & 1.5 & Physics \& Astronomy & 3.28 & 1.4 & 3.19 \\
\hline 6 & Materials Science & 1.68 & 0.4 & Physics \& Astronomy & 0.44 & 0.7 & 1.06 \\
\hline 7 & Materials Science & 2.57 & 1.5 & Chemistry & 0.53 & 0.7 & 1.55 \\
\hline 8 & Chemistry & 7.79 & 9.6 & Materials Science & 3.15 & 5.4 & 5.47 \\
\hline
\end{tabular}

quantitative scheme to describe the contribution of coauthors via weight coefficient. Basically weight coefficients for the first and corresponding authors are 1 for both, and the correspondence of the second, third, and the other authors are decreased sequentially. Weighted T-indicators of each candidate were obtained in Table 5. The weighted T-indicators were very similar to the normal T-indicators of both Candidates 3 (1.50 and 1.44, respectively) and Candidate 4 (2.69 and 2.11, respectively), showing their high research contributions to all publications; however, the big difference of these two indicators of Candidate 2 (1.60 and 0.77 , respectively) and Candidate 7 (1.55 and 0.91, respectively) demon- strated their un-ideal contribution to all publications. Consequently, the order of research performance of these candidates based on weighted T-indicator could be listed as Candidate 8, Candidate 4, Candidate 5, Candidate 3, Candidate 1, Candidate 7, Candidate 2 and Candidate 6, without the consideration of differences among disciplines.

As described above, the research performance of these 8 candidates was quantitatively analyzed via this assessment method, which could give helpful reference to the award funding committee but still need the comprehensive qualitative evaluation via peer reviews, to get a final reasonable evaluation result of research performance of 
Table 5. Weighted TJ-indicator of publication of 8 candidates. The data were collected from Scopus citation database at 20/09/2010.

\begin{tabular}{|c|c|c|c|c|c|}
\hline \multirow{2}{*}{ No. } & \multicolumn{2}{|l|}{ Discipline 1} & \multicolumn{2}{|c|}{ Discipline 2} & \multirow{2}{*}{$\begin{array}{l}\text { Average } \\
\mathrm{W}-\mathrm{TJ}_{\text {total }}\end{array}$} \\
\hline & Field & Weighted-TJ $\mathrm{T}_{1}$ & Field & Weighted- $\mathrm{TJ}_{2}$ & \\
\hline 1 & Physics \& Astronomy & 1.07 & Materials Science & 0.84 & 0.95 \\
\hline 2 & Engineering & 1.07 & Physics \& Astronomy & 0.48 & 0.77 \\
\hline 3 & Biochemistry, Genetics and Molecular Biology & 1.78 & Engineering & 1.1 & 1.44 \\
\hline 4 & Physics \& Astronomy & 4.17 & Engineering & 0.06 & 2.11 \\
\hline 5 & Engineering & 2.93 & Physics \& Astronomy & 1.12 & 2.02 \\
\hline 6 & Materials Science & 0.71 & Physics \& Astronomy & 0.67 & 0.69 \\
\hline 7 & Materials Science & 1.32 & Chemistry & 0.51 & 0.91 \\
\hline 8 & Chemistry & 6.19 & Materials Science & 2.29 & 4.24 \\
\hline
\end{tabular}

these candidates.

\section{Conclusion}

This new article assessment method, via the application of T-indicators, was established successfully for correcting differences among disciplines. An example was given to describe this whole assessment procedure which could not only give the research performance curve with year of candidate each, but also could provide the order of their research performance. Last but not least, because of the increasing citation times with time, the Table of the Mean of Citation Count of all TJU Publications is required to be updated at least twice annually.

\section{Acknowledgements}

We thank Prof. Chun-Ting Zhang of Tianjin University for helpful discussions and revisions. Ling Zhang thanks the financial support from The Ministry of education of Humanities and social science research fund plan/Youth Fund/Self-financing project, 11YJC870036.

\section{REFERENCES}

[1] L. Zhang, H. Zhao, Q. Li, J. Wang and X. Tan, "Establishment of Paper Assessment System Based on Acadmic Disciplinary Benchmarks,” Scientometrics, Vol. 84, No. 2, 2010, pp. 421-429. doi:10.1007/s11192-009-0132-9

[2] J. E. Hirsch, “An Index to Quantify an Individual's Scientific Research Output," Proceedings of the National Academy of Sciences of the United States of America, Vol. 102, No. 46, 2005, pp. 16569-16572. doi:10.1073/pnas.0507655102

[3] C. T. Zhang, "The E-Index, Complementing the H-Index for Excess Citations,” PLOS (Public Library of Science) ONE, Vol. 4, No. 5, 2009, p. e5429. doi:10.1371/journal.pone.0005429

[4] B. Jin, "H-Index: An Evaluation Indicator Proposed by Scientist,” Science Focus, Vol. 1, No. 1, 2006, pp. 8-9.

[5] C. T. Zhang, "A Proposal for Calculating Weighted Citations Based on Author Rank," EMBO (European Molecular Biology Organization) Reports, Vol. 10, No. 5, 2009, pp. 416-417. doi:10.1038/embor.2009.74 


\section{Appendix}

\begin{tabular}{|c|c|c|c|c|c|c|c|c|c|c|c|c|c|c|c|c|c|c|c|c|c|}
\hline \multirow{2}{*}{$\begin{array}{l}\quad \text { Subject } \\
\text { Agricultural } \\
\text { and Biological } \\
\text { Sciences }\end{array}$} & \multirow{2}{*}{$\begin{array}{c}\text { Total } \\
\text { Publication } \\
\\
388\end{array}$} & \multicolumn{2}{|c|}{2001} & \multicolumn{2}{|c|}{2002} & \multicolumn{2}{|c|}{2003} & \multicolumn{2}{|c|}{2004} & \multicolumn{2}{|c|}{2005} & \multicolumn{2}{|c|}{2006} & \multicolumn{2}{|c|}{2007} & \multicolumn{2}{|c|}{2008} & \multicolumn{2}{|c|}{2009} & \multicolumn{2}{|c|}{2010} \\
\hline & & 11 & 14.18 & 5 & 13 & 16 & 7.94 & 27 & 7.7 & 55 & 3.55 & 50 & 262 & 69 & 3.29 & 72 & 2.75 & 52 & 0.69 & 31 & 0.1 \\
\hline $\begin{array}{l}\text { Arts and } \\
\text { Humanities }\end{array}$ & 8 & 0 & 0 & 0 & 0 & 0 & 0 & 1 & 14 & 1 & 0 & 0 & 0 & 3 & 1.3 & 0 & 0 & 2 & 0 & 1 & 0 \\
\hline $\begin{array}{l}\text { Biochemistry, } \\
\text { Genetics and } \\
\text { Molecular } \\
\text { Biology }\end{array}$ & 1594 & 36 & 14.56 & 50 & 19.28 & 133 & 9.92 & 124 & 7.97 & 232 & 4.46 & 308 & 3.13 & 248 & 3.35 & 159 & 2.43 & 206 & 1.24 & 98 & 0.19 \\
\hline $\begin{array}{l}\text { Business, } \\
\text { Management } \\
\text { and Accounting }\end{array}$ & 274 & 0 & 0 & 2 & 15.5 & 4 & 0.25 & 2 & 0.5 & 17 & 0.47 & 22 & 0.5 & 54 & 0.59 & 30 & 0.1 & 113 & 0.04 & 30 & 0 \\
\hline $\begin{array}{l}\text { Chemical } \\
\text { Engineering }\end{array}$ & 3147 & 126 & 5.32 & 162 & 7.72 & 172 & 6.73 & 285 & 6.17 & 500 & 3.32 & 476 & 3.39 & 459 & 2.6 & 432 & 1.85 & 347 & 0.67 & 188 & 0.1 \\
\hline Chemistry & 2577 & 91 & 5.71 & 95 & 6.27 & 159 & 6.23 & 212 & 6.2 & 287 & 5.45 & 306 & 5.63 & 310 & 3.43 & 394 & 2.44 & 476 & 0.91 & 247 & 0.07 \\
\hline $\begin{array}{l}\text { Computer } \\
\text { Science }\end{array}$ & 2552 & 42 & 4.67 & 37 & 6.78 & 126 & 3.71 & 121 & 3.15 & 155 & 2.51 & 215 & 1.29 & 364 & 0.98 & 574 & 0.47 & 807 & 0.13 & 111 & 0.04 \\
\hline $\begin{array}{l}\text { Decision } \\
\text { Sciences }\end{array}$ & 199 & 4 & 14 & 0 & 0 & 1 & 4 & 2 & 34 & 6 & 7.83 & 15 & 3.73 & 14 & 1.93 & 49 & 0.29 & 104 & 0.08 & 4 & 0.25 \\
\hline $\begin{array}{l}\text { Earth and } \\
\text { Planetary } \\
\text { Sciences }\end{array}$ & 772 & 28 & 1.79 & 34 & 0.79 & 45 & 1.49 & 50 & 2.72 & 110 & 1.66 & 127 & 1.28 & 126 & 1.05 & 105 & 0.5 & 121 & 0.13 & 26 & 0 \\
\hline $\begin{array}{l}\text { Economics, } \\
\text { Econometrics } \\
\text { and Finance }\end{array}$ & 15 & 0 & 0 & 1 & 1 & 0 & 0 & 0 & 0 & 0 & 0 & 2 & 2.5 & 2 & 4 & 1 & 0 & 5 & 0 & 4 & 0 \\
\hline Energy & 1316 & 39 & 3.51 & 58 & 2.34 & 74 & 183 & 123 & 3.33 & 147 & 2.37 & 153 & 2.36 & 150 & 2.37 & 174 & 2.07 & 288 & 0.54 & 110 & 0.09 \\
\hline Engineering & 11176 & 318 & 2.65 & 429 & 3.39 & 580 & 2.96 & 1203 & 2.09 & 1492 & 1.88 & 1698 & 1.33 & 1534 & 1.11 & 1676 & 0.69 & 1608 & 0.31 & 638 & 0.03 \\
\hline $\begin{array}{l}\text { Environmental } \\
\text { Science }\end{array}$ & 589 & 12 & 3.25 & 21 & 9 & 22 & 5.55 & 31 & 6.13 & 56 & 6.41 & 82 & 3.82 & 95 & 3.99 & 78 & 2.28 & 134 & 0.66 & 58 & 0.03 \\
\hline $\begin{array}{l}\text { Health } \\
\text { Professions }\end{array}$ & 34 & 0 & 0 & 1 & 67 & 1 & 27 & 3 & 11.67 & 0 & 0 & 2 & 14.5 & 3 & 5 & 3 & 5 & 21 & 0.05 & 0 & 0 \\
\hline $\begin{array}{l}\text { Immunology } \\
\text { And } \\
\text { Microbiology }\end{array}$ & 54 & 14 & 20.93 & 13 & 10.08 & 12 & 15.5 & 15 & 8.07 & 13 & 10.08 & 18 & 6.72 & 19 & 7 & 11 & 4.18 & 19 & 2.89 & 20 & 0.2 \\
\hline $\begin{array}{l}\text { Materials } \\
\text { Science }\end{array}$ & 3985 & 102 & 7.73 & 156 & 7.02 & 172 & 8.5 & 292 & 5.08 & 471 & 3.92 & 537 & 4.32 & 536 & 3.44 & 589 & 1.93 & 811 & 0.62 & 319 & 0.06 \\
\hline Mathematics & 1057 & 20 & 3.6 & 19 & 4.74 & 20 & 1.55 & 43 & 3.3 & 59 & 3.8 & 94 & 1.86 & 176 & 1.07 & 174 & 0.95 & 356 & 0.19 & 96 & 0.03 \\
\hline Medicine & 478 & 3 & 5.67 & 7 & 11.86 & 11 & 5.73 & 26 & 3 & 23 & 1.96 & 47 & 3.81 & 84 & 2.04 & 83 & 1 & 141 & 0.38 & 53 & 0.04 \\
\hline Neuroscience & 21 & 1 & 13 & 1 & 2 & 0 & 0 & 1 & 23 & 0 & 0 & 4 & 8.75 & 2 & 3 & 2 & 1.5 & 4 & 1.25 & 6 & 0.33 \\
\hline Nursing & 5 & 0 & 0 & 0 & 0 & 0 & 0 & 0 & 0 & 0 & 0 & 1 & 5 & 0 & 0 & 1 & 3 & 1 & 3 & 2 & 0.5 \\
\hline $\begin{array}{l}\text { Pharmacology, } \\
\text { Toxicology, } \\
\text { Pharmaceutics }\end{array}$ & 271 & 3 & 3.67 & 7 & 32.14 & 10 & 7.4 & 15 & 103 & 31 & 148 & 26 & 2.5 & 42 & 1.45 & 52 & 1.58 & 58 & 0.48 & 27 & 0.07 \\
\hline $\begin{array}{l}\text { Physics and } \\
\text { Astronomy }\end{array}$ & 3958 & 117 & 3.84 & 166 & 4.55 & 228 & 4.24 & 317 & 4.31 & 575 & 3.07 & 593 & 2.69 & 548 & 1.97 & 610 & 1.26 & 773 & 0.44 & 31 & 0.38 \\
\hline Psychology & 4 & 1 & 44 & 1 & 38 & 0 & 0 & 0 & 0 & 0 & 0 & 0 & 0 & 0 & 0 & 2 & 2 & 0 & 0 & 0 & 0 \\
\hline Social Sciences & 214 & 0 & 0 & 0 & 0 & 1 & 2 & 3 & 21.67 & 6 & 0.67 & 11 & 1.82 & 51 & 1 & 63 & 0.56 & 71 & 0.35 & 8 & 0 \\
\hline Veterinary & 1 & 0 & 0 & 0 & 0 & 0 & 0 & 0 & 0 & 0 & 0 & 0 & 0 & 1 & 0 & 0 & 0 & 0 & 0 & 0 & 0 \\
\hline
\end{tabular}

